\title{
Dicloroisocianurato na prevenção do entupimento devido ao uso de águas ferruginosas em sistemas de irrigação por gotejamento ${ }^{1}$
}

\section{Dicloroisocianurato in the prevention of the clogging due to the use of rusted waters in drip irrigation}

\author{
Cristiani Campos Martins Busato ${ }^{2 *}$; Antônio Alves Soares ${ }^{3}$; \\ Márcio Mota Ramos ${ }^{3}$; Edvaldo Fialho dos Reis ${ }^{4}$; Camilo Busato ${ }^{5}$
}

Resumo

O objetivo deste trabalho foi avaliar o desempenho de um sistema de irrigação por gotejamento, aplicando água com elevado teor de ferro total e, ainda, avaliar a eficiência da cloração orgânica na prevenção do entupimento. $\mathrm{O}$ sistema de irrigação foi constituído de quatro subunidades de irrigação, que receberam os seguintes tratamentos com dicloro: $\left(\mathrm{N} 1=0, \mathrm{~N} 2=15, \mathrm{~N} 3=30\right.$ e N4 $=45 \mathrm{mg} \mathrm{L}^{-1}$ de cloro livre). A uniformidade de aplicação de água do sistema foi avaliada utilizando os coeficientes de uniformidade de Christiansen (CUC) e de Distribuição (CUD), a cada 100 horas de uso, durante 700 horas, antes e após a cloração. Também foi determinado o coeficiente de variação de vazão (CVq). Verificou-se uma redução nos valores do CUC e do CUD de 8,2 e 15,2\%, respectivamente, na subunidade N1, refletindo no aumento do CVq. A cloração com dicloroisocianurato de sódio nas dosagens de 15,30 e $45 \mathrm{mg} \mathrm{L}^{-1}$ previne o entupimento dos gotejadores.

Palavras-chave: Cloro, obstrução, ferro

\begin{abstract}
The objective of this work was to evaluate the performance of a drip irrigation system applying water with high concentration of total iron, and to evaluate the efficiency of organic chlorine to prevent emitters clogging. The system consisted of four subunits receiving the following of dichlorine treatments: (N1 $=0, \mathrm{~N} 2=15, \mathrm{~N} 3=30$ and $\mathrm{N} 4=45 \mathrm{mg} \mathrm{L}^{-1}$ of free chlorine). The uniformity of application of water was evaluated using the coefficients of uniformity of Christiansen (CUC) and of Distribution (CUD), every 100 hours of use, for 700 hours, before and after the chlorination. Also the discharge coefficient variation $(\mathrm{CVq})$ was evaluated. In the subunit with $\mathrm{N} 1$ there was a reduction in the values of CUC and CUD of 8,2 and $15,2 \%$, respectively. The chlorination with dichlorine of sodium in the dosages of 15 , 30 and $45 \mathrm{mg} \mathrm{L}^{-1}$ prevents the blockage of the dripper.
\end{abstract}

Key words: Chlorine, obstruction, iron

1 Parte da Dissertação de Mestrado apresentada pela primeira autora da Universidade Federal de Viçosa, UFV. Viçosa, MG.

2 Eng $^{\mathrm{a}} \mathrm{Agr}^{\mathrm{a}}$, D.Sc. Engenharia Agrícola, Instituto Federal do Espírito Santo, IFES Campus Itapina, Colatina, ES. E-mail: cristianicmartins@yahoo.com.br

3 Prof. do Dept ${ }^{\circ}$ de Engenharia Agrícola, UFV, Viçosa, MG. E-mail: aasoares@ufv.br; mmramos@ufv.br

4 Prof. do Dept ${ }^{\mathrm{O}}$ de Engenharia Rural, Universidade Federal do Espírito Santo, CCA/UFES, Alegre, ES. E-mail: edreis@cca.ufes.br

5 Doutorando da CCA/UFES, Alegre, ES. E-mail: camilobusato@yahoo.com.br

* Autor para correspondência 


\section{Introdução}

O sistema de irrigação por gotejamento apresenta uma série de características favoráveis ao desenvolvimento agrícola, em relação aos outros sistemas, como: maior eficiência operacional, disponibilidade da água diretamente na zona radicular da cultura, menor necessidade de mão-deobra e, além disso, a superfície molhada é menor, pois a água infiltra no solo formando um bulbo molhado, disponibilizando ao sistema radicular do vegetal a umidade necessária ao seu desenvolvimento. Por outro lado, a qualidade da água é um fator essencial, pois problemas de entupimento diminuem a eficiência do sistema (MARTINS, 2007).

Keller e Bliesner (1990) afirmam que os gotejadores são, reconhecidamente, projetados com pequenas seções de escoamento, visando proporcionar vazões menores, o que resulta em maior probabilidade de entupimento quando comparados aos aspersores. A precipitação química, a formação de filmes biológicos e os depósitos de partículas inorgânicas no interior de gotejadores são riscos presentes nesses sistemas de irrigação (BASTOS, 1999).

A obstrução dos emissores está diretamente relacionada à qualidade da água de irrigação. O ferro e o manganês, em elevados teores, são os principais causadores dessas obstruções. Estes elementos, ao entrar em contato com o oxigênio atmosférico ou incorporado à água, oxidam-se passando para as formas $\mathrm{Fe}^{3+}$ e $\mathrm{Mn}^{4+}$, de baixo coeficiente de solubilidade, e precipitam-se facilmente no interior das tubulações e dos emissores, impedindo ou dificultando a passagem normal da água (MARTINS, 2000).

A avaliação sistemática do sistema de irrigação localizada e o monitoramento da qualidade da água são essenciais para prevenir o entupimento (COELHO et al., 2008). Para reduzir o entupimento nos emissores, são sugeridas diversas técnicas na literatura, que são selecionadas em função da fonte causadora.
A prevenção da obstrução dos emissores e das linhas de distribuição nos sistemas de irrigação localizada é mais econômica, e consequentemente preferível, em relação à recuperação depois do entupimento (RESENDE; COELHO; PIEDADE, 2000). De modo geral, uma das medidas mais utilizadas é o tratamento químico da água, com o uso da acidificação e da cloração para controlar o entupimento de origem biológica (COELHO et al., 2008).

Os derivados clorados são muito utilizados na prevenção de entupimento dos gotejadores. $\mathrm{Na}$ década de 70, surgiram os chamados derivados clorados orgânicos, denominados "cloraminas orgânicas", destacando-se o dicloroisocianurato de sódio e o ácido tricloroisocianúrico (DYCHDALA, 1991). O dicloroisocianurato de sódio é um composto clorado orgânico que apresenta ausência de substâncias indesejáveis e metais pesados, sendo extremamente seguro para o manuseio e inócuo ao ser hidrolizado. Outra característica vantajosa no seu uso no dia a dia é o $\mathrm{pH}$ da sua solução a $1 \%$, que varia de 6,0 a 8,0 , enquanto o $\mathrm{pH}$ de outros derivados clorados como hipoclorito de sódio e/ou de cálcio variam de 11,0 a 12,5. Com o uso dos derivados clorados de origem orgânica, a probabilidade de formação de trihalometanos é muito pequena ou nula quando comparada com os níveis formados pelos derivados clorados de origem inorgânica (MACÊDO, 1997).

De acordo com Bernardo, Soares e Mantovani (2008), um dos principais parâmetros para avaliação de um sistema de irrigação é a determinação da uniformidade de aplicação de água sobre a área irrigada. Segundo Soares, Ramos e Lucato Júnior (1993), a uniformidade de aplicação de água influencia, diretamente, a produtividade da cultura e o consumo de energia no bombeamento de água, sendo que a produtividade tende a aumentar com a uniformidade de aplicação da irrigação.

A uniformidade de aplicação de água, em sistemas de irrigação por gotejamento, pode ser expressa através de vários coeficientes, destacando- 
se o coeficiente de uniformidade de Christiansen (CUC) e o coeficiente de uniformidade de distribuição (CUD).

Assim, este trabalho teve como objetivo avaliar o desempenho de um sistema de irrigação por gotejamento aplicando água com elevado teor de ferro total e avaliar a eficiência da cloração orgânica na prevenção do entupimento.

\section{Material e Métodos}

O experimento foi realizado na área experimental do Instituto Federal do Espírito Santo - Campus Santa Teresa, em Santa Teresa-ES, situada a $19^{\circ} 48^{\prime}$ de latitude Sul e 40 40' de longitude Oeste, em uma altitude de 174 m, numa região que apresenta sérios problemas na irrigação devido à água ferruginosa.

A água utilizada na irrigação apresentava 3,57 mg L ${ }^{-1}$ de ferro total, sendo captada de uma lagoa localizada próxima ao local onde foi realizado o experimento.

Foi montado um sistema de irrigação por gotejamento, com tubogotejadores autocompensantes, com as seguintes especificações técnicas: vazão nominal de $2,3 \mathrm{~L} \mathrm{~h}^{-1}$, diâmetro interno de 14,6 mm e espaçamento entre tubogotejadores de $0,75 \mathrm{~m}$.

O sistema foi dividido em quatro unidades operacionais correspondente a diferentes concentrações de cloro: N1 (sem aplicação de cloro), N2 (15 mg L-1 de cloro livre), N3 (30 mg $\mathrm{L}^{-1}$ de cloro livre) e N4 (45 $\mathrm{mg} \mathrm{L}^{-1}$ de cloro livre). Foram instaladas doze linhas laterais de $20 \mathrm{~m}$ de comprimento contendo cadauma 24 tubogotejadores. Foi utilizado um conjunto motobomba de $1 \mathrm{cv}$ com sistema de filtragem com filtro de disco de 120 mesh (Figura 1). O tempo de operação total do sistema foi de 700 h, com o sistema funcionando, em média, $15 \mathrm{~h}$ por dia, dotado de temporizador para ligar e desligar o sistema nos horários programados.

A cloração com dicloroisocianurato de sódio (65\%) foi realizada após a avaliação de uniformidade do sistema, a cada 100 h de operação. Após a aplicação do cloro, a válvula de cada linha lateral era fechada, deixando-se a solução agir por $12 \mathrm{~h} \mathrm{e}$, no dia seguinte, realizava-se uma nova avaliação da uniformidade, afim de avaliar o efeito da cloração, perfazendo um total de 8 avaliações.

O dicloroisocianurato de sódio era diluído em um recipiente graduado e, posteriormente, aplicado na tubulação, nos níveis (N2, N3 e N4), a uma taxa de injeção de $10 \mathrm{~L} \mathrm{~h}^{-1}$, por um injetor de fertilizantes tipo Venturi.

Os dados de vazão foram interpretados por meio dos coeficientes de uniformidade de Christiansen (CUC) e de Distribuição (CUD), representados pelas Eqs. 1 e 2, respectivamente (KELLER; KARMELLI, 1975; BERNARDO; SOARES; MANTOVANI, 2008), sendo também determinado o coeficiente de variação da vazão $(\mathrm{CVq})$, devido ao processo de fabricação. Observa-se na Tabela 1 os critérios para classificação dos coeficientes de uniformidade.

$$
C U C=100\left(1-\frac{\sum_{i=1}^{n}\left|q_{i}-q_{m}\right|}{n q_{m}}\right)
$$

em que:

$C U C=$ coeficiente de uniformidade de Christiansen (\%);

$q_{i}=$ vazão de cada emissor $\left(\mathrm{L} \mathrm{h}^{-1}\right)$;

$q_{m}=$ vazão média dos emissores $\left(\mathrm{L} \mathrm{h}^{-1}\right)$; e

$n=$ número de emissores avaliados.

$$
C U D=100 \frac{q_{25 \%}}{q_{m}}
$$

em que:

$C U D=$ coeficiente de uniformidade de distribuição (\%);

$q 25 \%=$ média dos $25 \%$ menores valores de vazão observados $\left(\mathrm{L} \mathrm{h}^{-1}\right)$;

$q_{m}=$ vazão média dos emissores $\left(\mathrm{L} \mathrm{h}^{-1}\right)$. 
Figura 1. Esquema do sistema de irrigação montado no experimento.

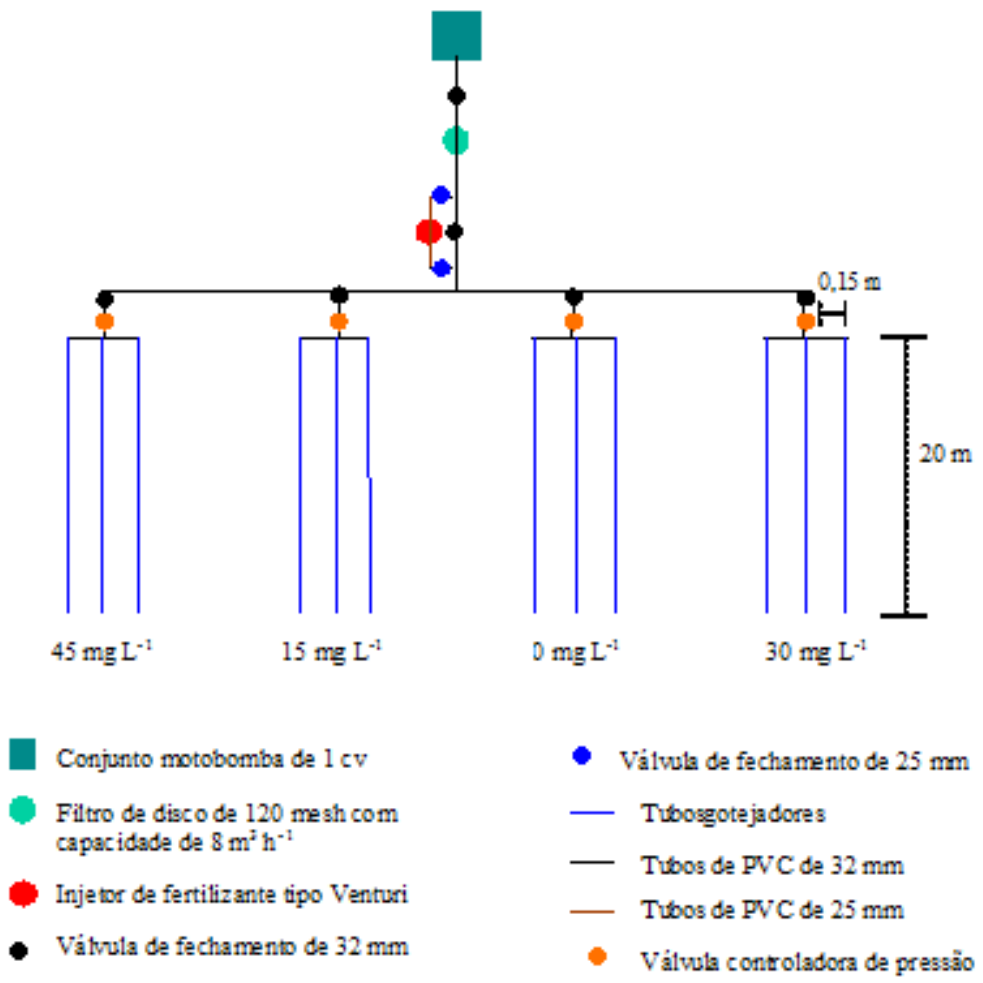

Tabela 1. Critérios para classificação dos sistemas de irrigação quanto ao CUC e CUD.

\begin{tabular}{ccc}
\hline CUC (\%)* & CUD (\%)** & Avaliação \\
\hline $90-100$ & $90-100$ & Excelente \\
$80-90$ & $80-90$ & Bom \\
$70-80$ & $70-80$ & Razoável \\
$60-70$ & $<70$ & Ruim \\
\hline
\end{tabular}

Fonte: *Mantovani (2002); ** Bralts (1986).

O experimento foi conduzido em parcelas subdivididas, tendo nas parcelas quatro doses de cloro livre $(\mathrm{N} 1=0, \mathrm{~N} 2=15, \mathrm{~N} 3=30$ e N4 $=45 \mathrm{mg}$ $\left.\mathrm{L}^{-1}\right)$ e, nas subparcelas, os tempos de funcionamento $(0,100,200,300,400,500,600$ e 700 horas $)$ no delineamento inteiramente casualizado com três repetições. Os dados foram submetidos à análise de variância e as médias foram comparadas utilizandose o teste de Tukey a 5\% de probabilidade utilizandose o programa SAEG (SAEG, 2007).

\section{Resultados e Discussão}

Observa-se na Figura 2 que houve redução nos valores médios do CUC com a utilização de água ferruginosa, sem tratamento químico $\left(\mathrm{N} 1=0 \mathrm{mg} \mathrm{L}^{-1}\right)$, onde se verificou um decréscimo da uniformidade ao longo do tempo de funcionamento, devido ao entupimento provocado pelo alto teor de ferro total presente na água. $\mathrm{O}$ sistema foi classificado como excelente no início das avaliações (CUC $=95,23 \%)$, mas apresentou redução no valor de CUC de $8,2 \%$, 
passando a ser classificado como bom. Nos níveis N2, N3 e N4, a aplicação do dicloroisocianurato de sódio proporcionou melhoria dos valores do CUC, mantendo-os sempre acima de 90\%, ficando o sistema classificado como excelente durante todo o período de avaliação.
Segundo Mantovani e Ramos (1994), quanto maior o valor do CUC, menor é a lâmina de irrigação necessária para alcançar a produtividade máxima e, de acordo com Bernardo, Soares e Mantovani (2008), o limite mínimo de CUC aceitável para irrigação por gotejamento é de $80 \%$.

Figura 2. Valores médios do CUC, antes (Ava) e após a cloração (Reava), nos Níveis N1, N2, N3 e N4.
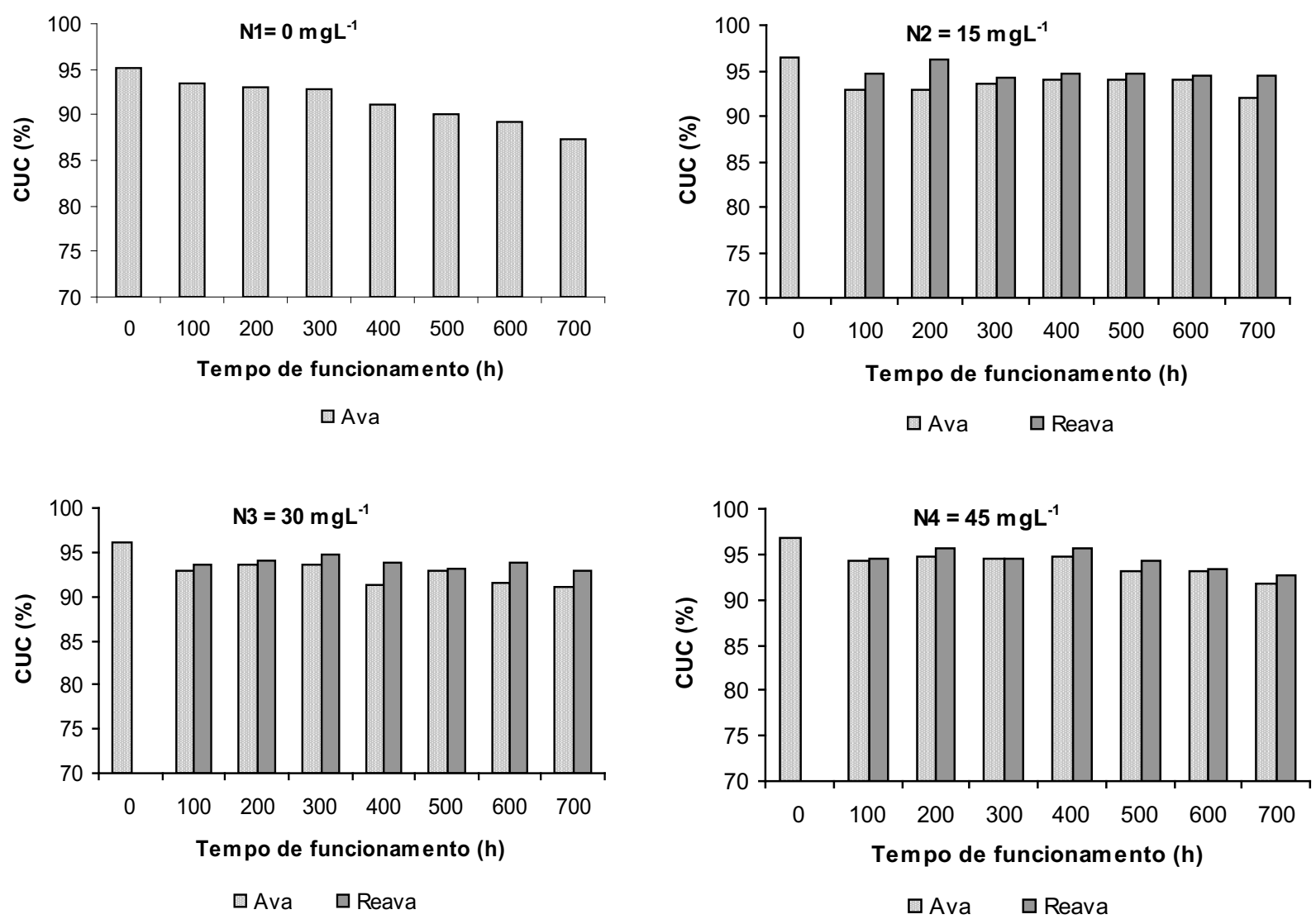

O CUD foi mais sensível às variações da uniformidade de aplicação de água pelo efeito do entupimento que o CUC, como era de se esperar, pois, em seu cálculo, utilizam-se os valores médios dos $25 \%$ menores valores das vazões. Assim, observase na Figura 3, que na subunidade de irrigação que não recebeu a aplicação do dicloro (N1), a uniformidade de aplicação de água ferruginosa decresceu consideravelmente, ao longo do tempo, devido ao entupimento dos tubogotejadores. O sistema de irrigação por gotejamento, que de

acordo com o CUD, inicialmente era classificado como excelente, atingiu um nível regular, quando se estabeleceu comparação entre a primeira e a última avaliação, apresentando uma redução de 15,2\% no seu valor. Entretanto, nos níveis N2, N3 e N4, a aplicação do cloro orgânico proporcionou melhoria dos valores do CUD, mantendo a uniformidade em faixas adequadas para o funcionamento de sistemas de irrigação por gotejamento, permitindo a classificação dos mesmos como excelente em praticamente todas as avaliações (Figura 3). 
Figura 3. Valores médios do CUD, antes (Ava) e após a cloração (Reava), nos Níveis N1, N2, N3 e N4.
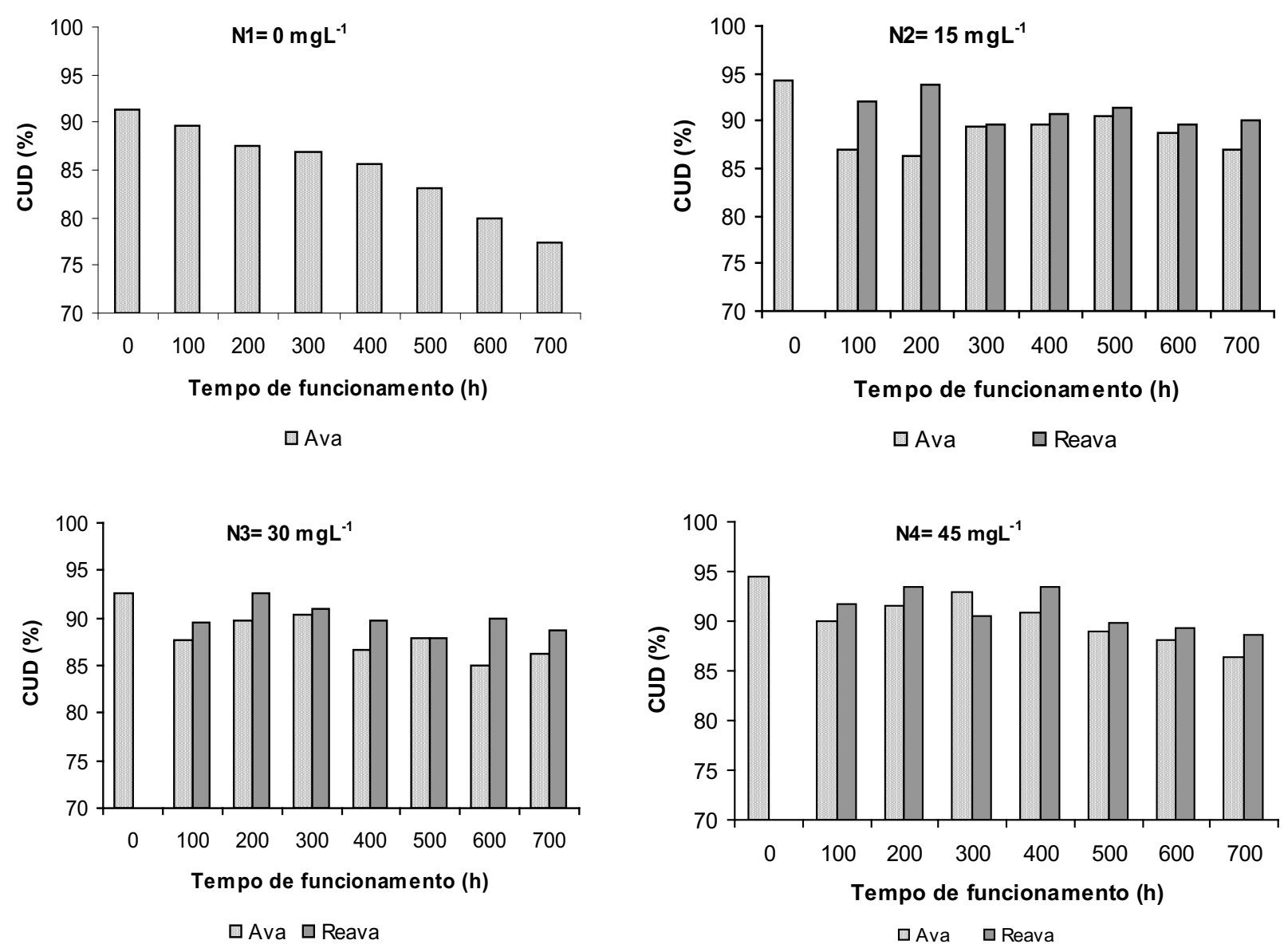

Verifica-se, na Figura 4, que o $\mathrm{CVq}$ foi aumentando com o tempo no Nível N1. Como esta subunidade não recebeu aplicação de cloro, o processo de entupimento ocasionou variação na vazão dos gotejadores, o que refletiu no aumento no CVq. Após a aplicação do produto nos Níveis N2, N3 e N4, o CVq diminuiu, sendo que, em geral, o produto o manteve sempre menor que $10 \%$, constatado nas reavaliações da uniformidade.

Nos tubogotejadores, também foi verificada a formação de mucilagem de ferrobactérias que afetou a uniformidade de distribuição de água (Figura 5).

Os resultados demonstraram que a cada $100 \mathrm{~h}$ de funcionamento, o CUC e o CUD diminuíam, mas, com a aplicação do dicloroisocianurato de

sódio, ocorria uma recuperação dos valores de uniformidade pela ação do cloro promovendo, assim, desobstrução dos gotejadores, indicando que o produto é capaz de ajudar na limpeza das linhas e emissores quando se utiliza água com elevado teor de ferro total.

Estão apresentados na Tabela 2 os resultados do teste de Tukey ao nível de 5\% de probabilidade e valores médios do CUC, CUD e CVq. Como não houve diferença nos valores dos coeficientes avaliados nos níveis 2, 3 e 4, ou seja, a menor dose testada $\left(15 \mathrm{mg} \mathrm{L}^{-1}\right)$ foi eficiente na prevenção de entupimento. Recomenda-se testar menores concentrações para verificar a dosagem mínima que poderia ser usada. 
Figura 4. Valores médios do CVq, antes (Ava) e após a cloração (Reava), nos Níveis N1, N2, N3 e N4.
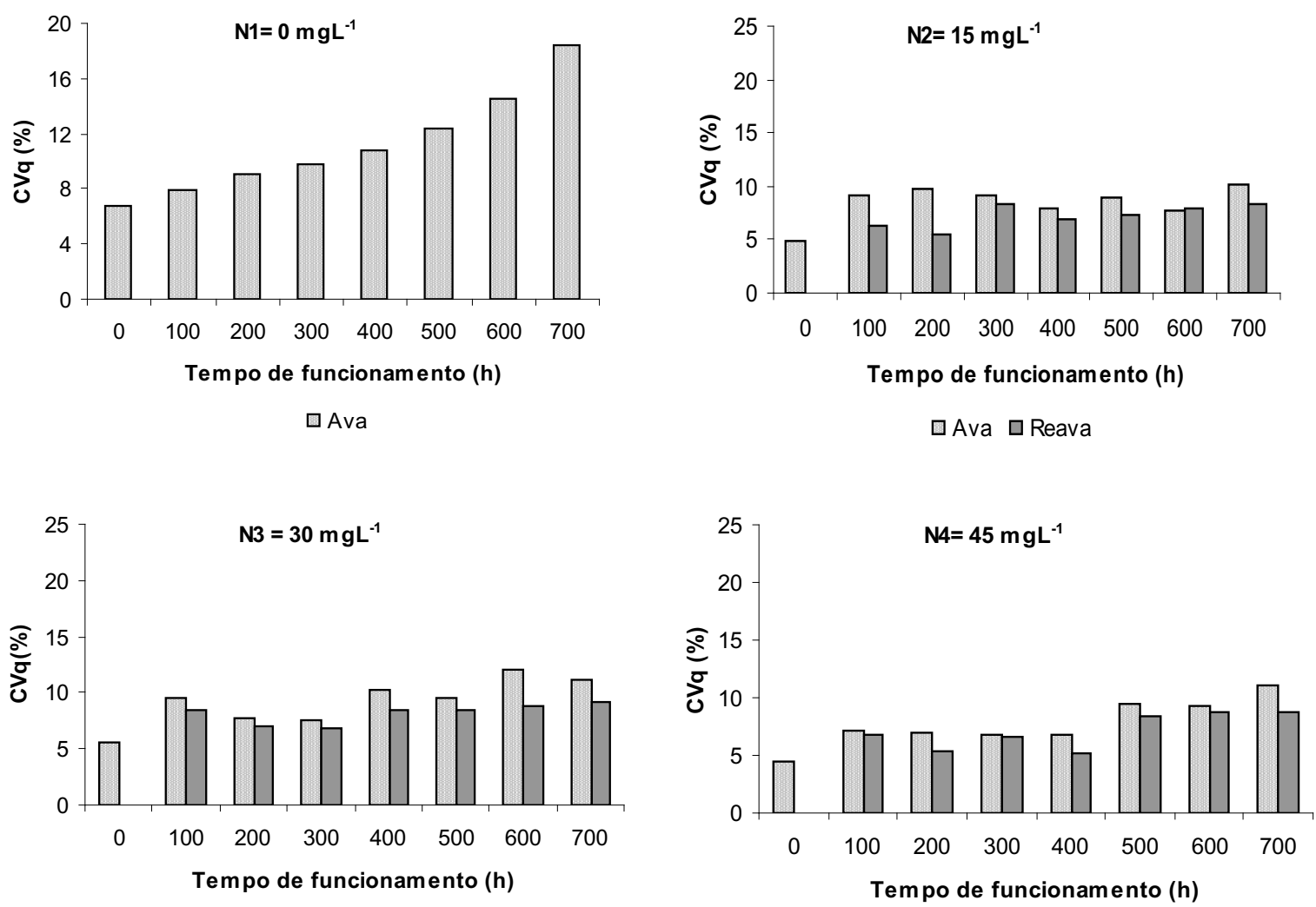

口Ava $\square$ Reava

\section{$\square$ Ava $\quad$ Reava}

Figura 5. Interior do registro com acúmulo de ferro e mucilagem de ferrobactérias (A) e tubogotejador novo e após $700 \mathrm{~h}$ de funcionamento aplicando água ferruginosa (B).
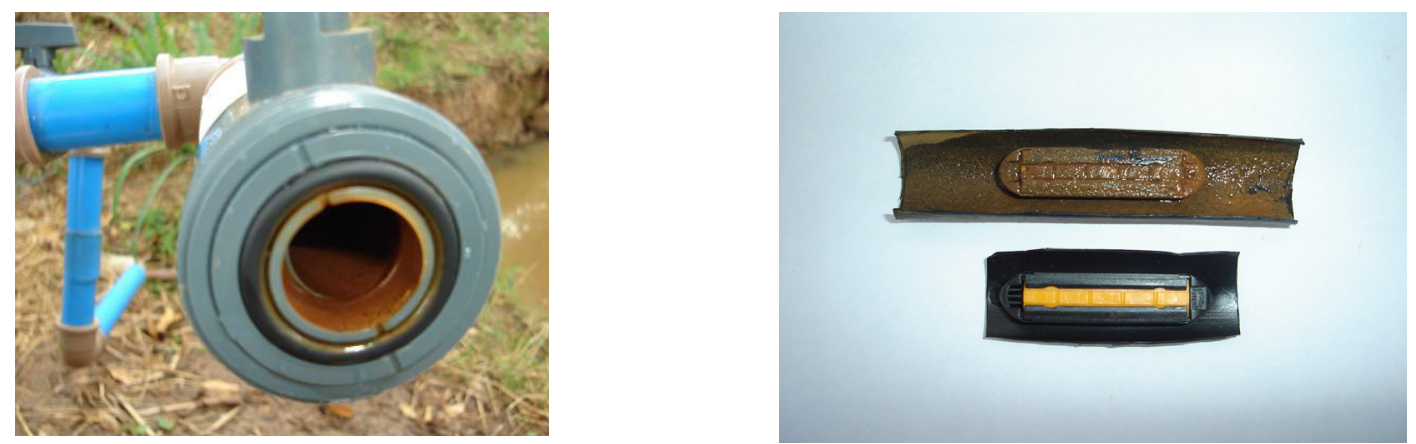

Tabela 2. Teste de média e valores médios do CUC, CUD e CVq.

\begin{tabular}{cccc}
\hline Nível & CUC & CUD & CVq \\
\hline N1 & $91,25 \mathrm{~b}$ & $84,25 \mathrm{~b}$ & $0,118 \mathrm{~b}$ \\
N2 & $94,94 \mathrm{a}$ & $91,46 \mathrm{a}$ & $0,069 \mathrm{a}$ \\
N3 & $93,97 \mathrm{a}$ & $90,22 \mathrm{a}$ & $0,078 \mathrm{a}$ \\
N4 & $94,66 \mathrm{a}$ & $91,43 \mathrm{a}$ & $0,067 \mathrm{a}$ \\
\hline
\end{tabular}

*Médias com mesma letra minúscula entre colunas, não apresentam diferenças significativas ao nível de 5\% de probabilidade pelo teste de Tukey. 


\section{Conclusões}

O uso de água com $3,57 \mathrm{mg} \mathrm{L}^{-1}$ de ferro total sem o devido tratamento em sistemas de irrigação por gotejamento proporciona redução nos valores do CUC e CUD e aumento do CVq

A cloração com dicloroisocianurato de sódio nas dosagens acima de $15 \mathrm{mg} \mathrm{L}^{-1}$ previne o entupimento dos gotejadores.

\section{Referências}

BASTOS, R. K. X. Fertirrigação com águas residuárias. In: FOLEGATT, M. V. (Coord.). Fertirrigação - citrus, flores, hortaliças. Guaíba: Agropecuária, 1999. p. 297291.

BERNARDO, S.; SOARES, A. A.; MANTOVANI, E. C. Manual de irrigação. 8. ed. Viçosa: Ed. UFV, 2008. 625 p.

BRALTS, V. F. Field performance and evaluation. In: NAKAYAMA, F. S.; BUCKS, D. A. (Ed.). Trickle irrigation for crop production. Amsterdam: Elsevier, 1986. p. 216-240. (Development in Agricultural Engineering, 9).

COELHO, R. D.; TEIXEIRA, M. B.; MELO, R. F.; PAULA, M. C. Caracterização hidráulica de gotejadores autocompensantes expostos à aplicação dinâmica de cloro livre (Parte II). Irriga, Botucatu, v. 13, n. 3, p. 411425, 2008

DYCHDALA, G. R. Chlorine and chlorine compounds. In: BLOCH, S. S. (Ed.). Disinfection, sterilization and preservation. 4. ed. Philadelfia: Lea \& Febiger, 1991. p. 131-151.

KELLER, J.; BLIESNER, R. D. Sprinkle and trickle irrigation. New York: Avibook, 1990. 649 p.
KELLER, J.; KARMELI, D. Trickle irrigation design. Glendora: Rain Bird Sprinklers Manufacturing Corp., 1975. $133 \mathrm{p}$.

MACÊDO, J. A. B. Determinação de Trihalometanos em águas de abastecimento público e indústria de alimentos. 1997. Dissertação (Doutorado em Ciência e Tecnologia de Alimentos) - Universidade Federal de Viçosa, Viçosa, 1997.

MANTOVANI, E. C. Avalia: manual do usuário. Viçosa: DEA/UFV-PNP\&D/Café Embrapa, 2002.

MANTOVANI, E. C.; RAMOS, M. M. Manejo da irrigação. In: COSTA, E. F.; VIEIRA, R. F.; VIANA, P. A. Quimigação: aplicação de produtos químicos e biológicos via irrigação. Brasília: Empresa Brasileira de Pesquisa Agropecuária, Centro de Pesquisa de Milho e Sorgo, EMBRAPA-SSI, 1994. p. 129-158.

MARTINS, C. M. Efeito da cloração orgânica na uniformidade de distribuição de água em sistema de irrigação por gotejamento utilizando água ferruginosa. 2007. Dissertação (Mestrado em Engenharia Agrícola) Universidade Federal de Viçosa, Viçosa.

MARTINS, M. L. N. Dinâmica do ferro e do manganês no hipolímnio do reservatório serra azul em Minas Gerais. Belo Horizonte: Departamento de Engenharia Sanitária, Universidade Federal de Minas Gerais, 2000.

RESENDE, R. S.; COELHO, R. D.; PIEDADE, S. M. S. Eficiência da cloração da água de irrigação no tratamento de gotejadores com entupimento de causa biológica. Revista Brasileira de Engenharia Agrícola e Ambiental, Campina Grande, v. 4, n. 3, p. 382-389, 2000.

SISTEMA PARA ANÁLISES ESTATÍSTICAS - SAEG. versão 9.1. Viçosa: Fundação Arthur Bernardes, UFV, 2007. CD-ROM.

SOARES, A. A.; RAMOS, M. M.; LUCATO JÚNIOR, J. Uso racional de energia elétrica em sistemas de irrigação tipo pivô-central no estado de Minas Gerais. In: CONGRESSO BRASILEIRO DE ENGENHARIA AGRÍCOLA, 22., 1993, Ilhéus. Anais... Ilhéus: SBEA, 1993. CD-ROM. 